\title{
Extracellular Polymeric Substance (EPS) Production by Nostoc minutum under Different Laboratory Conditions
}

\author{
Dante S. Videla Pereyra, Susana G. Ferrari* \\ Laboratorio de Microbiología, Universidad Nacional de San Luis, Ejército de los Andes y Estado de Israel, \\ San Luis, Argentina \\ Email: ${ }^{*}$ sferrari@unsl.edu.ar
}

Received 26 February 2016; accepted 24 April 2016; published 27 April 2016

Copyright (C) 2016 by authors and Scientific Research Publishing Inc.

This work is licensed under the Creative Commons Attribution International License (CC BY). http://creativecommons.org/licenses/by/4.0/

c) (†) Open Access

\section{Abstract}

A study of the influence of different laboratory growth conditions on the biomass and EPS production by Nostoc minutum, a diazothophic cyanobacterium locally isolated, was carried out. Two culture media were tested, with or without $\mathrm{NaNO}_{3}$ addition, and three luminous intensities: low (4530 lux), intermediate (7300 lux) and high (9860 lux). BW 3 medium was better than BG11 for $N$. minutum growth, with maximal values of biomass concentration (4.98 DO) and the highest growth rate $\left(0.019 \mathrm{~h}^{-1}\right)$ at 9860 lux of light intensity. A progressive increase in culture viscosity of $N$. minutum cultures was observed, for stirred condition and non-diazotrophic growth in BG11 medium, together with the production of maximal EPS concentration $(2.485 \mathrm{~g} / \mathrm{L})$. On the other hand, the EPS production in $\mathrm{BW}_{3}$ medium was maximal in diazotrophic conditions, both for still (1.66 $\mathrm{g} / \mathrm{L})$ and stirred $(2.56 \mathrm{~g} / \mathrm{L})$ cultures. The different yields of EPS reported for each condition, results in the requirement of a species-specific optimization of the cultivation conditions for the exploitation of an efficient technology for the production of $N$. minutum EPS.

\section{Keywords}

Exopolysaccharides, Cyanobacteria, Nostoc minutum

\section{Introduction}

Cyanobacteria are photosynthetic microorganisms with morphological diversity and metabolic versatility. They are included in a wide range of microorganisms that are able to synthesize and secrete extracellular polymeric

*Corresponding author.

How to cite this paper: Pereyra, D.S.V. and Ferrari, S.G. (2016) Extracellular Polymeric Substance (EPS) Production by Nostoc minutum under Different Laboratory Conditions. Advances in Microbiology, 6, 374-380.

http://dx.doi.org/10.4236/aim.2016.65036 
substances (EPS) mainly of polysaccharidic nature, which can remain covalently linked or loosely bound to the cell surface, or be liberated to the surrounding medium [1].

Due to their interesting physicochemical properties, the EPS have found applications in many industries like textiles, adhesives, paint, food, and beverage, among others [2]. The EPS released into the culture medium can be easily recovered making cyanobacteria one of the most attractive sources of new polymers [3]. Besides, the monosaccharide composition of cyanobacterial EPS has some peculiar characteristics when compared with polymers produced by other microorganisms, such as the presence of one or two uronic acids, constituents rarely found in the EPS produced by other microbial groups [4]. The factors affecting EPS production during microorganism growth have been studied previously. Several works are available that report the effects of light intensity both in diazotrophic and non-diazotrophic conditions. In general, the EPS production showed a positive linear effect with light intensity especially in the presence of combined nitrogen for different Nostoc species [5], Arthrospira platensis [6] and Cyanothece sp. CCY 0110 [7]. However, the different Nostoc species yielded contradictory results indicating that EPS production is affected both by nutritional and environmental parameters even to a species-specific level [8]. Additionally, the synthesis of increased amounts of EPS could be part of a stress response. Some of the major stress factors are the presence of metal ions [9], the availability of carbon substrates and the balance between carbon and other limiting nutrients [10] [11]. The cyanobacterium Cyanospira capsulata responded to changes in metabolic carbon flux, showing an improvement in the synthesis of EPS with enhanced carbon flux [12]. The aim of this work was to study the influence of different laboratory growth conditions on the biomass and EPS production by Nostoc minutum, a diazothophic cyanobacterium locally isolated.

\section{Materials and Methods}

\subsection{Microorganism and Culture Media}

The cyanobacterium Nostoc minutum [13] was used in this study. Stock cyanobacterial cultures were maintained in the $\mathrm{BW}_{3}$ medium with the following composition (g/L): $\mathrm{K}_{2} \mathrm{HPO}_{4} 0.25 ; \mathrm{NaHCO}_{3} 0.5 ; \mathrm{MgSO}_{4} 0.7 \mathrm{H}_{2} \mathrm{O} 0.375$; $\mathrm{CaCl}_{2}$ 0.4; $\mathrm{NaCl}$ 4; $\mathrm{NaNO}_{3}$ 0.5; $\mathrm{FeCl}_{3} \cdot 6 \mathrm{H}_{2} \mathrm{O}$ 0.024; EDTA.2 $\mathrm{H}_{2} \mathrm{O}$ 0.0625; micronutrients $6.25 \mathrm{ml}$ [14] and BG11 medium with the following composition (g/L): $\mathrm{NaNO}_{3} 1.5 ; \mathrm{K}_{2} \mathrm{HPO}_{4} \cdot 3 \mathrm{H}_{2} \mathrm{O} 0.04 ; \mathrm{MgSO}_{4} \cdot 7 \mathrm{H}_{2} \mathrm{O} 0.075 ; \mathrm{CaCl}_{2} \cdot 2 \mathrm{H}_{2} \mathrm{O}$ 0.036; $\mathrm{C}_{6} \mathrm{H}_{8} \mathrm{O}_{7}$ 0.06; $\mathrm{C}_{6} \mathrm{H}_{5+4 y} \mathrm{Fe}_{\mathrm{x}} \mathrm{N}_{\mathrm{y}} \mathrm{O}_{7}$ 0.06; $\mathrm{Na}_{2}$ EDTA 0.0005; $\mathrm{Na}_{2} \mathrm{CO}_{3} \cdot\left(\mathrm{H}_{2} \mathrm{O}\right)$ 0.010; micronutrients $1 \mathrm{ml}$ [15]. All strains were unicyanobacterial and non-axenic, but the number of observed associated bacteria was very low. All reagents used were of analytical grade, obtained from Merck.

\subsection{Culturing Procedures}

All culturing procedures were performed aseptically. Stockcultures, $10 \mathrm{~mL}(0.15 \mathrm{~g} / \mathrm{L})$, were used to inoculate either erlenmeyers flasks (still cultures) or glass columns (stirred cultures). Cultivation was carried out in sterilised photobiorectors consisting of $250 \mathrm{~mL}$ Erlenmeyer flasks equipped with a device for aseptic removal of samples (still cultures) or $250 \mathrm{ml}$ glass columns $37 \mathrm{~mm}$ i.d., containing $200 \mathrm{ml}$ of BW3 or BG11 medium with or without the addition of $\mathrm{NaNO}_{3}$ and mixed through air injection with an aeration flow of $6.13 \mathrm{~mL} / \mathrm{seg}$ (stirred cultures). The aeration was performed with filter-sterilized air. The cultures were run for 2 weeks (14 days) at $30^{\circ} \mathrm{C}$ under permanent lighting of 4530 (low intensity), 7300 luxes (intermediate intensity) and 9860 luxes (high intensity).

\subsection{Analytical Determinations}

Cyanobacterial growth was estimated by optical density (OD) at $580 \mathrm{~nm}$ every $48 \mathrm{~h}$. EPS production was determinated after cultures reached the stationary phase, qualitatively by Alcian blue tintion and India ink, and quantitatively by dry weight determinations. The experiment was conducted in triplicates and values were expressed as their mean.

EPS was quantified by the method of Mondal et al. modified [16], culture broth were decanted into $50 \mathrm{ml}$ centrifuge tubes, vortexed for $5 \mathrm{~min}$ and centrifuged at $10,000 \mathrm{rpm}$ for $30 \mathrm{~min}$ at $4^{\circ} \mathrm{C}$ to remove cells. The supernatants were collected and 2.0 volume of acetone $80 \%$ was added and kept overnight at $4^{\circ} \mathrm{C}$ for precipitation. The pellets, collected by centrifugation at 12,000 rpm for $10 \mathrm{~min}$, were dissolved in deionized distilled water and dialyzed overnight at $4{ }^{\circ} \mathrm{C}$ against deionized distilled water. Dialyzed materials were lyophilized and 
weighed (AdventurerTM OHAUS Corp. USA). Experiments were performed three times to ensure reproducibility.

For physical characterization of the EPS, it was determined the electric charge by precipitation with cetylperidium chloride (CPC) [17]. The dried EPS (5 mg) was dissolved in $5 \mathrm{ml}$ of $0.05 \mathrm{M} \mathrm{NaCl}$; thereafter, $10 \% \mathrm{CPC}$ solution was added into it until no more precipitate of EPS-CPC complex was formed. The rheological behaviour was studied using a Brookfield programmable rheometer at $25^{\circ} \mathrm{C}$ following a standard method with some modification [18]. The EPS solution (2.0\%) was prepared in deionized double distilled water. The $\mathrm{pH}$ of the EPS solution was adjusted to 7.0 using $1 \mathrm{~N} \mathrm{HCl}$ and $1 \mathrm{M} \mathrm{NaOH}$.

\section{Results and Discussion}

\subsection{Growth and Biomass Production}

An increase in biomass production and specific growth rate with the increment of light intensity were observed. However, for still cultures the light intensity showed a slight incidence. Different authors reported the importance to consider this parameter because it is often found as a limiting factor in culture systems [19] [20]. The efficient air-lift stirring of the glass columns plays a crucial rol for reducing shading between cells, thus allowing to obtain higher values of biomass than in still cultures. BW3 medium was better than BG11 for $N$. minutum growth, with maximal values of biomass concentration (4.98 DO) and the highest specific growth rate $\left(0.019 \mathrm{~h}^{-1}\right)$ at 9860 lux of light intensity. The $\mathrm{BW}_{3}$ medium have 50 times $\mathrm{NaHCO}_{3}$ concentration and 5 times $\mathrm{MgSO}_{4} \cdot 7 \mathrm{H}_{2} \mathrm{O}$ and $\mathrm{K}_{2} \mathrm{HPO}_{4}$ than BG11, composition that was optimal for $N$. minutum growth. The presence of combined nitrogen also had a positive effect on growth and specific growth rate $(\mu)$ under all the conditions assayed. The lowest values of biomass and specific growth rate were obtained for diazotrophic conditions in $\mathrm{BG} 11^{0}$ medium. In fact, biomass production was more affected by the availability of combined nitrogen than by light intensity (Table 1).

$N$. minutum cells are enclosed in a fibrous matrix at the cell wall surface that has a structural coherence sufficient to exclude particles (e.g. India ink, see Figure 1(A)). The observation of the preparations stained with Alcian Blue and India ink under the light microscope, showed an EPS production according to that determined by dry weight technique. For non diazotrophic cultures, it was observed a gradual increase in EPS production with the days that was coinciding with a remarkable increase in the culture viscosity. The viscosity of the cultures was maximal at 14 days in BG11 medium (Figure 1(B) and Figure 1(C)). Besides, the Alcian Blue stain is

Table 1. Influence of N, light intensity and stirring on N. minutum biomass production.

\begin{tabular}{cccccc}
\hline & & \multicolumn{2}{c}{ Biomass (DO) } & \multicolumn{2}{c}{ Growth rate $\left(\mathbf{h}^{-1}\right)$} \\
\hline $\begin{array}{c}\text { Culture } \\
\text { Medium }\end{array}$ & $\begin{array}{c}\text { Light } \\
\text { Intensity (lux) }\end{array}$ & Still Cultures & Stirred Cultures & Still Cultures & Stirred Cultures \\
\hline BG11 & 4530 & $0.64 \pm 0.02$ & $3.13 \pm 1.53$ & nd & $0.011 \pm 0.03$ \\
BG110 & 4530 & $0.56 \pm 0.06$ & $0.69 \pm 0.23$ & nd & $0.001 \pm 0.08$ \\
BW3 & 4530 & $0.72 \pm 1.03$ & $3.73 \pm 0.06$ & $0.011 \pm 2.55$ & $0.013 \pm 0.07$ \\
BW30 & 4530 & $0.70 \pm 0.02$ & $3.02 \pm 0.07$ & nd & $0.010 \pm 0.01$ \\
BG11 & 7300 & $0.86 \pm 0.07$ & $3.09 \pm 0.02$ & nd & $0.009 \pm 0.11$ \\
BG110 & 7300 & $0.67 \pm 0.01$ & $1.07 \pm 0.01$ & nd & $0.004 \pm 0.40$ \\
BW3 & 7300 & $0.85 \pm 0.05$ & $4.02 \pm 2.03$ & $0.012 \pm 0.12$ & $0.014 \pm 0.06$ \\
BW30 & 7300 & $0.80 \pm 0.02$ & $3.54 \pm 0.07$ & nd & $0.010 \pm 0.06$ \\
BG11 & 9860 & $1.18 \pm 0.02$ & $3.04 \pm 0.05$ & nd & $0.012 \pm 0.11$ \\
BG110 & 9860 & $0.85 \pm 0.04$ & $1.89 \pm 0.04$ & nd & $0.006 \pm 0.07$ \\
BW3 & 9860 & $\mathbf{1 . 3 0} \pm 0.02$ & $4.98 \pm 0.02$ & $\mathbf{0 . 0 1 6} \pm 0.10$ & $\mathbf{0 . 0 1 9} \pm 0.03$ \\
BW30 & 9860 & $1.22 \pm 0.03$ & $3.99 \pm 0.09$ & nd & $0.015 \pm 0.02$ \\
\hline
\end{tabular}

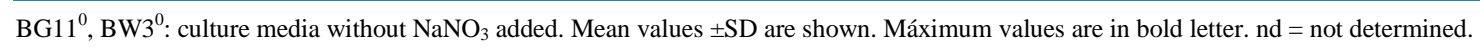


specific to acid mucopolysaccharide [21]. The EPS produced by N. minutum was stainable with Alcian Blue (Figure 1(B)), which indicate that it is mainly composed of polysaccharides.

\subsection{EPS Production}

Figure 2 shows EPS production by N. minutum. Both the still and stirred cultures followed a similar pattern, with best yields of EPS for non diazotrophic BG11 and diazotrophic $\mathrm{BW}_{3}$ cultures. The maximal concentration of EPS (2.87 g/L) was obtained with BG11 medium under stirred conditions and high irradiance (Figure 2(B)).

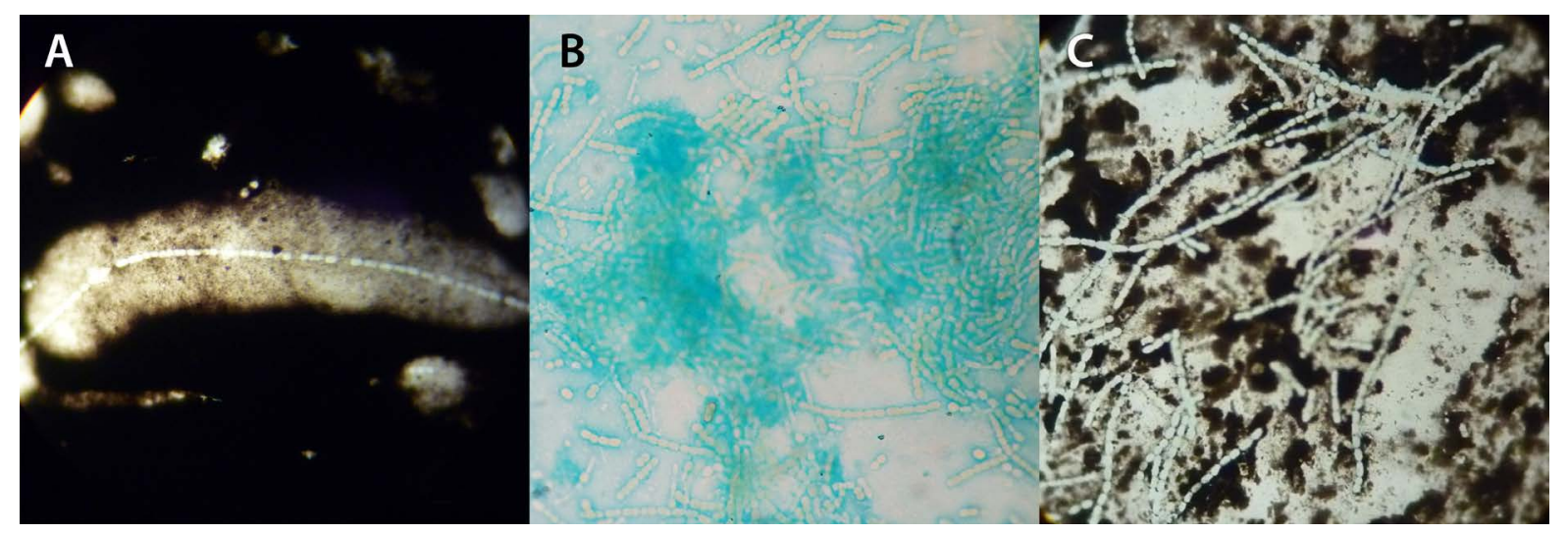

Figure 1. Microphotograph of: negatively stained preparation (India ink) showing the thickness of the capsule which surrounds the trichomes of $N$. minutum strain (A), EPS stained with Alcian blue (B) and India ink (C) in BG11 medium (14 days).

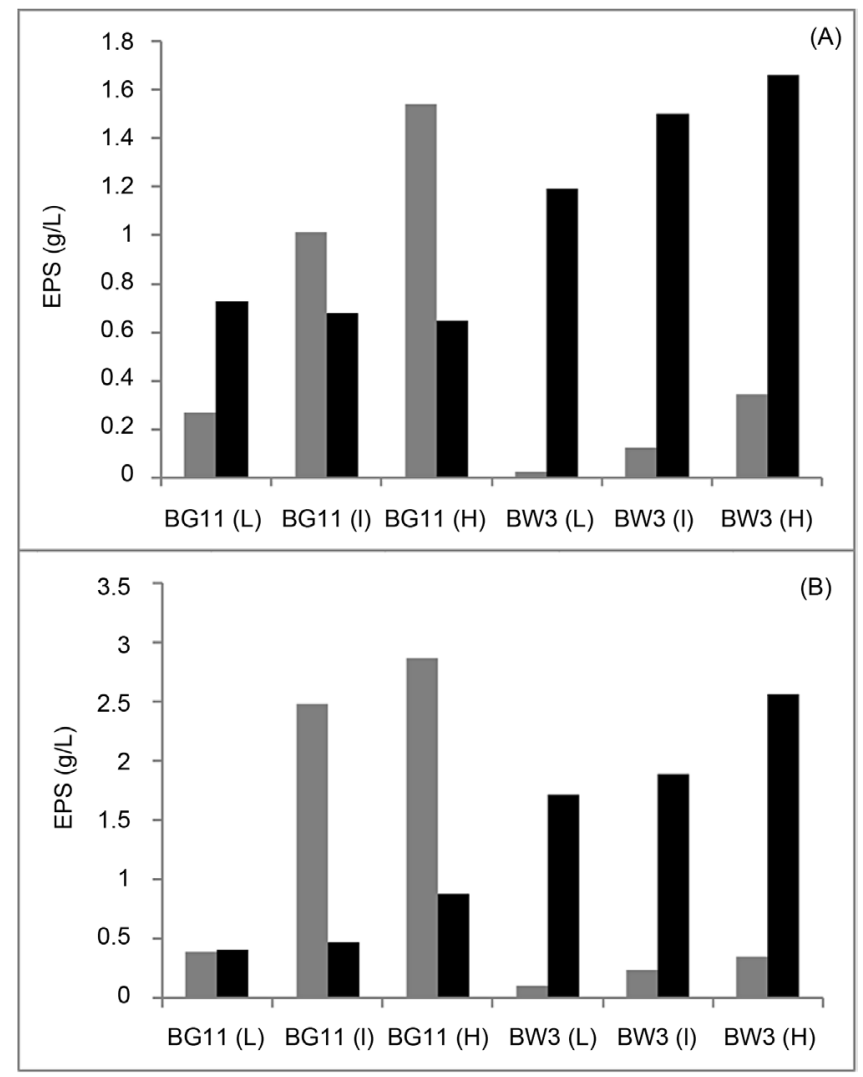

Figure 2. EPS production by N. Minutum that were grown: in still (A) or stirred (B) cultures, diazotrophic ( $\mathbf{\square})$ and nondiazotrophic $(\square)$ in low light (L), intermediate light (I) and high light (H), all data are means of three replicates. 
There is a marked difference between the main components of the two culture media used. While, both BG11 ${ }^{0}$ and $\mathrm{BW}^{0}$ have no $\mathrm{NaNO}_{3}$ added, BG11 have three times $\mathrm{NaNO}_{3}$ concentration than $\mathrm{BW}_{3}$. The absence of $\mathrm{NaNO}_{3}$ could be a stress factor favourable for EPS synthesis. In fact, a number of diazotrophic strains of Nostoc have shown to produce EPS under N2-fixing conditions, with reduce production when grown on an exogenous $\mathrm{N}$ source [22]. However, the EPS production by $N$. minutum was maximal when the $\mathrm{NaNO}_{3}$ concentration was tripled. Similar results were informed by Nicolaus et al. for Anabaena WSAF with 56 mg/L in BG11 and 22 $\mathrm{mg} / \mathrm{L}$ in $\mathrm{BG} 11^{0}$ media [23]. The yields of EPS were in agreement with other values reported for cyanobacteria by Otero and Vincenzini [22] with $3.5 \mathrm{~g} / \mathrm{L}$ of total carbohidrates and $1.8 \mathrm{~g} / \mathrm{L}$ for soluble ones. On the other hand, the EPS production by $N$. minutum growing in $\mathrm{BW}_{3}$ medium was maximal in diazotrophic conditions, both for still $(1.66 \mathrm{~g} / \mathrm{L})$ and stirred $(2.56 \mathrm{~g} / \mathrm{L})$ cultures showing that EPS production varies with nutrient availability [24] and environmental conditions [25]. The progressive increase in culture viscosity of $N$. minutum stirred cultures observed when growing non diazotrophically in BG11 medium, may be due to the release of large amounts of EPS. On the contrary, this phenomenon was reported for the cyanobacteria Cyanospira capsulata growing diazotrophically [26] [27]. N. minutum released the EPS while the capsule that surrounds the cells became minimal, in contrast, the unicellular cyanobacterium Cyanothece sp showed the solubilization of the external part while the thickness of the capsule remained almost constant [11]. EPS produced by N. minutum showed precipitation with CPC, indicating the presence of acidic groups. The EPS include different classes of macromolecules such as proteins, polysaccharides, uronic acids and other compounds not yet fully characterised [28]. The precipitation of EPS with CPC allow to confirm the anionic nature of the EPS due to interaction of quaternary ammonium ions of the CPC with the acidic groups to form a polysaccharide-CPC complex [17], showing interesting properties for metal uptake in bioremediation field [29]. The viscosity of $N$. minutum EPS showed a decrease with an increase in the shear rate. Such rheological behaviour is the characteristic of a typical pseudoplastic non-Newtonian fluid [30] and agrees with results reported by Khattar et al. [31].

\section{Acknowledgements}

This work was supported by the Secretaría de Ciencia y Técnica, UNSL, Argentina.

\section{References}

[1] De Philippis, R. and Vincenzini, M. (2003) Outermost Polysaccharidic Investments of Cyanobacteria: Nature, Significance and Possible Applications. Recent Research Developement in Microbiology, 7, 13-22.

[2] Richert, L., Golubic, S., Le Guédès, R., Ratiskol, J., Payri, C. and Guezennec, J. (2005) Characterization of Exopolysaccharides Produced by Cyanobacteria Isolated from Polynesian Microbial Mats. Current Microbiology, 51, 379-384. http://dx.doi.org/10.1007/s00284-005-0069-z

[3] Chakraborty, T. and Pal, R. (2014) An Overview of Cyanobacterial Exopolysaccharides: Features, Composition and Effects of Stress Exposure. International Journal of Life Sciences, 8, 1-9. http://dx.doi.org/10.3126/ijls.v8i4.10891

[4] Pereira, S., Zille, A., Micheletti, E., Moradas-Ferreira, P., De Philippis, R. and Tamagnini, P. (2009) Complexity of Cyanobacterial Exopolysaccharides: Composition, Structures, Inducing Factors and Putative Genes Involved in Their Biosynthesis and Assembly. FEMS Microbiology Reviews, 33, 917-941. http://dx.doi.org/10.1111/j.1574-6976.2009.00183.x

[5] Otero, A. and Vincenzini, M. (2004) Nostoc (Cyanophyceae) Goes Nude: Extracellular Polysaccharides Serve as a Sink for Reducing Power under Unbalanced C/N Metabolism. Journal of Phycology, 40, 74-81. http://dx.doi.org/10.1111/j.0022-3646.2003.03-067.x

[6] Trabelsi, L., Ben Ouada, H., Bacha, H. and Ghoul, M. (2009) Combined Effect of Temperature and Light Intensity on Growth and Extracellular Polymeric Substance Production by the Cyanobacterium Arthrospira platensis. Journal of Applied Phycology, 21, 405-412. http://dx.doi.org/10.1007/s10811-008-9383-8

[7] Mota, R., Guimarães, R., Büttel, Z., Rossi, F., Colica, G., Silva, C.J., Santos, C., Gales, L., Zille, A., De Philippis, R., Pereira, S.B. and Tamagnini, P. (2013) Production and Characterization of Extracellular Carbohydrate Polymer from Cyanothece sp. CCY 0110. Carbohydrate Polymers, 15, 1408-1415. http://dx.doi.org/10.1016/j.carbpol.2012.10.070

[8] De Philippis, R. and Vincenzini, M. (1998) Exocellular Polysaccharides from Cyanobacteria and Their Posible Applications. FEMS Microbiology Reviews, 22, 151-175. http://dx.doi.org/10.1111/j.1574-6976.1998.tb00365.x

[9] Yadav, K.K., Kumar Mandal, A. and Chakraborty, R. (2013) Copper Susceptibility in Acinetobacter junii BB1A Is Related to the Production of Extracellular Polymeric Substances. Antonie van Leeuwenhoek, 104, 261-269.

http://dx.doi.org/10.1007/s10482-013-9946-9 
[10] Moreno, J., Vargas, M.A., Olivares, H., Rivas, J. and Guerrero, M.G. (1998) Exopolysaccharide Production by the Cyanobacterium Anabaena sp. ATCC 33047 in Batch and Continuous Culture. Journal of Biotechnology, 60, 175-182. http://dx.doi.org/10.1016/S0168-1656(98)00003-0

[11] De Philippis, R., Margheri, M.C., Pelosi, E. and Ventura S. (1993) Exopolysaccharide Production by a Unicellular Cyanobacterium Isolated from a Hypersaline Hábitat. Journal of Applied Phycology, 5, 387-394. http://dx.doi.org/10.1007/BF02182731

[12] De Philippis, R., Sili, C. and Vincenzini, M. (1996) Response of an Exopolysaccharide-producing Heterocystous Cyanobacterium to Changes in Metabolic Carbon Flux. Journal of Applied Phycology, 8, 275-281. http://dx.doi.org/10.1007/BF02178570

[13] Ferrari, S., Guzmán, G., Silva, P., Alcaráz, L., Silva, H. and González, D. (2004) Captación de Cadmio por Biomasa Libre o Inmovilizada de Nostoc minutum (Cianobacteria Filamentosa). Acta Toxicologica Argentina, 12, 19-22.

[14] Silva, H.J. and Cortiñas, T.I. (1994) Vertical Thin-Layer Photoreactor for Controlled Cultivation of Cyanobacteria. World Journal of Microbiology and Biotechnology, 10, 145-148. http://dx.doi.org/10.1007/BF00360875

[15] Ilavarasi, A., Mubarakali, D., Praveenkumar, R., Baldey, E. and Thajuddin, N. (2011) Optimization of Various Growth Media to Freshwater Microalgae for Biomass Production. Biotechnology, 10, 540-545. http://dx.doi.org/10.3923/biotech.2011.540.545

[16] Mondal, S., Chandra, K., Maiti, D., Ojha, A.K., Das, D., Roy, S.K., Ghosh, K., Chakarborty, I. and Islam, S.S. (2008) Chemical Analysis of a New Fucoglucan Isolated from an Edible Mush-room, Termitomyces robustus. Carbohydrate Research, 343, 1062-1070. http://dx.doi.org/10.1016/j.carres.2008.02.017

[17] Scott, J.E. (1965) Fractionation by Precipitation with Quaternary Ammonium Salts. In: Whislter, R.K., Ed. Methods in Carbohydrate Chemistry, General Polysaccharide, Vol. 5, Academic Press, New York, 38-44.

[18] Gauri, S.S., Mandal, S.M., Mondal, K.C., Dey, S. and Pati, B.R. (2009) Enhanced Production and Partial Characterization of an Extracellular Polysaccharide from Newly Isolated Azotobacter sp. SSB81. Bioresource Technology, 100, 4240-4243. http://dx.doi.org/10.1016/j.biortech.2009.03.064

[19] Qiang, H. and Richmond, A. (1996) Productivity and Photosynthetic Efficiency of Spirulina platensis as Affected by Light Intensity, Algal Density and Rate of Mixing in a Flat Plate Photobioreactor. Journal of Applied Phycology, 8, 139-145. http://dx.doi.org/10.1007/BF02186317

[20] Zhang, D., Dechatiwongse, P., del Rio-Chanona, E.A., Maitland, G.C., Hellgardt, K. and Vassiliadis, V.S. (2015) Modelling of Light and Temperature Influences on Cyanobacterial Growth and Biohydrogen Production. Algal Research, 9, 263-274. http://dx.doi.org/10.1016/j.algal.2015.03.015

[21] Sheehan-Hrapchak (1980) Theory and Practice of Histotechnology. The CVV Mosby Company, Saint Louis, 162.

[22] Otero, A. and Vincenzini, M. (2003) Extracellular Polysaccharide Synthesis by Nostoc Strains as Affected by N Source and Light Intensity. Journal of Biotechnology, 102, 143-152. http://dx.doi.org/10.1016/S0168-1656(03)00022-1

[23] Nicolaus, B., Panico, A., Lama, L., Romano, I., Manca, M.C., De Giulio, A., et al. (1999) Chemical Composition and Production of Exopolysaccharides from Representative Members of Heterocystous and Non-Heterocystous Cyanobacteria. Phytochemistry, 52, 639-647. http://dx.doi.org/10.1016/S0031-9422(99)00202-2

[24] Ricciardi, A., Parente, E., Crudele, M.A., Zanetti, F., Scolari, G. and Mannazzu, I. (2002) Exopolysaccharide Production by Streptococcus thermophilus SY: Production and Preliminary Characterization of the Polymer. Journal of Applied Microbiology, 92, 297-306. http://dx.doi.org/10.1046/j.1365-2672.2002.01487.x

[25] Bahat-Samet, E., Castro-Sowinski, S. and Okon, Y. (2004) Arabinose Content of Extracellular Polysaccharide Plays a Role in Cell Aggregation of Azospirillum brasilense. FEMS Microbiology Letters, 237, 195-203. http://dx.doi.org/10.1111/j.1574-6968.2004.tb09696.x

[26] De Philippis, R., Sili, C., Tassinato, G., Vincenzini, M. and Materassi, R. (1991) Effects of Growth Conditions on Exopolysaccharide Production by Cyanospira capsulata. Bioresource Technology, 38, 101-104. http://dx.doi.org/10.1016/0960-8524(91)90138-A

[27] Lapasin, R., Pricl, S., Bertocchi, C., Navarini, L., Cesaro, A. and De Philippis, R. (1992) Rheology of Culture Broths and Exopolysaccharide of Cyanospira capsulata at Different Stages of Growth. Carbohydrate Polymers, 17, 1-10. http://dx.doi.org/10.1016/0144-8617(92)90017-K

[28] Parikh, A. and Madamwar, D. (2006) Partial Characterization of Extracelular Polysaccharides from Cyanobacteria. Bioresource Technology, 97, 1822-1827. http://dx.doi.org/10.1016/j.biortech.2005.09.008

[29] Shah, V., Ray, A., Garg, N. and Medamwar, D. (2000) Characterization of the Extracelular Polysaccharide Produced by a Marine Cyanobacterium, Cyanothece sp ATCC 51142, and its Exploitation Toward Metal Removal from Solutions. Current Microbiology, 40, 274-278. http://dx.doi.org/10.1007/s002849910054

[30] Ma, L. and Barbosa-Canovas, G.V. (1997) Viscoelastic Properties of Xanthan Gels Interacting with Cations. Journal of 
Food Science, 62, 1124-1128. http://dx.doi.org/10.1111/j.1365-2621.1997.tb12227.x

[31] Khattar, J.I., Singh, S., Jindal, D.P., Kaur, N., Singh, Y., Rahi, P. and Gulati, A. (2010) Isolation and Characterization of Exopolysaccharides Produced by the Cyanobacterium Limnothrix redekei PUPCCC 116. Applied Biochemistry and Biotechnology, 162, 1327-1338. http://dx.doi.org/10.1007/s12010-010-8922-3 